\title{
Caffeine Adsorption by Fique Bagasse Biochar Produced at Various Pyrolysis Temperatures
}

\section{YANED MILENA CORREA-NAVARRO ${ }^{1,2}$, JUAN CARLOS MORENO-PIRAJÁN², LILIANA GIRALDO ${ }^{3}$ and PAOLA RODRÍGUEZ-ESTUPIÑAN ${ }^{2}$}

\author{
${ }^{1}$ Grupo de Investigación En Estudios Ambientales en Aguas y Suelos. Departamento de Química, \\ Universidad de Caldas, Calle 65 No. 26-10, Manizales, Colombia. \\ ${ }^{2}$ Grupo de Sólidos Porosos y Calorimetría. Departamento de Química, Universidad de los Andes, \\ Cra 1a No. 18A-10, Bogotá D.C., Colombia. \\ ${ }^{3}$ Grupo de Calorimetría. Departamento de Química, Universidad Nacional de Colombia, \\ Cra 30 No. 45-03, Bogotá D.C., Colombia. \\ *Corresponding author E-mail: jumoreno@uniandes.edu.co
}

http://dx.doi.org/10.13005/ojc/350205

(Received: January 08, 2019; Accepted: March 28, 2019)

\begin{abstract}
Biochar obtained from agricultural residues is ever more recognized as a multifunctional porous solid for multiples applications. In this study, fique bagasse biochars were produced at different temperatures and their corresponding deashing. These materials were investigated about physicochemical properties and adsorption capability of caffeine. The $\mathrm{pH}$ solution was an influential parameter, and it was determined that a $\mathrm{pH}=2.0$ for washed biochar and $\mathrm{pH}=6.0$ for not washed biochar were the best conditions for adsorption. Langmuir, Freundlich and Redlich-Peterson isotherms models provided a good fit for the experimental data, indicating a surface and multi-layer adsorption. From the adsorption capacity at equilibrium of fique bagasse biochars it was concluded that $\mathrm{pH}$-dependent interactions, hydrogen bonding and $\pi-\pi$ stacking interaction were found to be responsible for caffeine adsorption. The results allow to visualize the biochar obtained from fique bagasse as a sustainable alternative for the waste derived from the production of the cabuya.
\end{abstract}

Keywords: Micropollutants, Waste management, Contaminant removal, Aqueous solution, Emerging organic contaminant.

\section{INTRODUCTION}

The adsorbents derived from carbonaceous materials have been studied for a long time, research carried out in this area in the last two decades have shown the importance that these solids have in the treatment of contaminated environments ${ }^{1}$. Biochars are part of this carbon rich porous materials and are defined as materials produced from the thermochemical conversion of biomass in an environment with limited oxygen ${ }^{2}$; in obtaining them, variables such as raw material, method and

This is an Open Access article licensed under a Creative Commons license: Attribution 4.0 International (CC- BY). Published by Oriental Scientific Publishing Company @ 2018 
temperature have an important effect on product yield and as well as in composition ${ }^{3}$. Biochars have long been used in agriculture as a soil supplement; in addition, many studies have shown promising results for the elimination of various types of molecules such as hydrocarbons, organic contaminants and some metallic ions present in municipal or industrial wastewater, which has led to the use of these porous materials in the search for new alternatives for the removal of contaminants from the water. However, these adsorptive properties have only been recognized in recent years and are comparable to those of activated carbon but biochars are cheaper and more sustainable ${ }^{4}$.

In recent decades a group of compounds called emerging contaminants (EC) have been detected in different aquatic environments at concentrations in the range $1 \mathrm{ng} / \mathrm{L}-{ }^{1} \mu \mathrm{g} / \mathrm{L}$. This group includes different compounds such as pesticides, hormones, pharmaceuticals and personal care products, among others ${ }^{5,6,7,8}$. These contaminants may be natural or synthetic substances that are not routinely monitored in the environment; however, they are known to have known or suspected undesirable effects on the health of humans and ecosystems. These compounds may not be completely removed from water by conventional treatments, which is why studies are required to remove these types of molecules from an aqueous phase in a novel and efficient manner ${ }^{5,8,9}$.

Caffeine (CFN) is considered an emerging pollutant, and has been found in various studies on surface water and wastewater, perhaps because it is the central nervous system stimulant most consumed worldwide, with an average of 70-76 $\mathrm{mg} /$ person/day. This molecule is commonly used in beverages, as an adjuvant to analgesic drugs and in anorectics ${ }^{10}$. On the other hand, caffeine is used as an anthropogenic marker ${ }^{11}$ and has been detected at a concentration of $5.5 \mu \mathrm{g} / \mathrm{L}$ in the Otun river, the water supply system of Pereira city (Colombia) ${ }^{12}$.

The agroindustrial process of fique fiber (Furcraea spp.) generate 15000 tons of bagasse residue per hectare. This material is left in soil, it and its leachates reach the river waters contaminating them. However, due to the physicochemical composition, which indicates that bagasse is a lignocellulosic waste biomass ${ }^{13}$, it becomes a potential substrate for biochar production.
In the search for new alternatives for the use of fique bagasse, this work aims to evaluate this biomass to production of biochar and its application in the adsorption of the emerging contaminant caffeine. For such, the porous materials obtaining from fique bagasse were used as a adsorbent in six different types. For all adsorbents optimum $\mathrm{pH}$ conditions were obtained and adsorption equilibrium isotherms were evaluated.

\section{MATERIALS AND METHODS}

\section{Reagents}

Caffeine (CFN) was purchased from Merck $\&$ Co. in analytical purity $(>99 \%)$. CFN solutions were prepared by dilution from a stock solution (1000 $\mathrm{mg} / \mathrm{L}$ ) to appropriate concentrations when needed. $\mathrm{KBr}$ (grade FTIR) was Panreac and the other chemical reagents used were analytical grade.

\section{Biochar preparation}

Fique bagasse (FB) was collected on a farm in Aranzazu (Caldas, Colombia) after fiber extraction. The $\mathrm{FB}$ was dried at $100^{\circ} \mathrm{C}$ until constant weigh. Biomass were then pyrolyzed at three different temperatures $\left(650,750\right.$ y $\left.850^{\circ} \mathrm{C}\right)$ using a horizontal furnace Thermolyne. The experiments were performed under an oxygen free atmosphere by passing nitrogen through the reactor. For each run heating rate and residence time were fixed at $1^{\circ} \mathrm{C} / \mathrm{min}$ for $60 \mathrm{~min}$, respectively. The biochars were left to cool, and a portion of each of the solids obtained were washed with purified water until constant $\mathrm{pH}$, and dried at $120^{\circ} \mathrm{C}$, so six solids were obtained. In this work, the biochars washed are labeled as BchL-650, BchL-750, BchL-850 or BchS-650, BchS-750, BchS-850 the not washed.

\section{Biochar characterization}

The topographic and elemental analysis of biochar surface was carried out by scanning electron microscopy (SEM) using a (JEOL, JSM 6490-LV) with an X-ray scattered energy detector (EDS). Biochar samples were gold coated prior to viewing $^{3}$. Thermogravimetric analysis (TGA) was performed between $25-900^{\circ} \mathrm{C}$ at a heating rate of $5^{\circ} \mathrm{C} / \mathrm{min}$ with a (Hitachi, TGA/STA7200). Nitrogen gas was used as an inert purge gas at flow rate of around $100 \mathrm{~mL} / \mathrm{min}^{14}$. The surface functional groups on the biochar were studied by Fourier transform infrared spectroscopy on a spectrometer (Shimadzu, 
FR-racer-100), the spectra were recorded in the 400-4000 $\mathrm{cm}^{-1}$ wavenumber range. The pellet was prepared by mixing a sample ( $0.1 \mathrm{mg}$ each) with $\mathrm{KBr}$ (100 mg) in a mortar pestle and resultant mixtures were placed in an oven at $105^{\circ} \mathrm{C}$ for $24 \mathrm{~h}$ to prevent interference like water vapor or carbon dioxide molecules ${ }^{15}$.

pH was measured by preparing a suspension of $10 \mathrm{mg}$ of adsorbent in $20 \mathrm{~mL}$ of deionized water and stirred for $24 \mathrm{~h}$, after that the $\mathrm{pH}$ was measured with a pH meter (Hanna Instruments, HI 2211)2. The point of zero charge (PZC) of the samples was determined by mass titration method. Slurries of different mass were prepared by mixing the biochar $(50-500 \mathrm{mg}$ ) with $10 \mathrm{~mL}$ of $0.1 \mathrm{M} \mathrm{NaCl}$. The $\mathrm{pH}$ of the slurries were measured after shaking for 48 hours. Plotting the equilibrium $\mathrm{pH}$ as a function of solid weight a curve was obtained. The equilibrium $\mathrm{pH}$ at the plateau of the curve cis defined to the $\mathrm{PZC}^{16}$.

Surface acidity and basicity of biochars were determined by Boehm's titration method. In brief, $100 \mathrm{mg}$ of biochar sample were placed in a $50 \mathrm{~mL}$ vial with the following $0.05 \mathrm{~N}$ solutions: sodium hydroxide $\mathrm{NaOH}$, sodium carbonate $\mathrm{Na}_{2} \mathrm{CO}_{3}$, sodium bicarbonate, $\mathrm{NaHCO}_{3}$, or hydrochloric acid $\mathrm{HCl}$. The vials were sealed and shaken in an orbital shaker for $48 \mathrm{~h}$, then $5 \mathrm{ml}$ of each filtrate was taked and the excess of base and acid was titrated with $\mathrm{HCl}$ and $\mathrm{NaOH}$, respectively. The number of acidic sites of various types was calculated under the assumption that $\mathrm{NaOH}$ neutralize carboxyl, phenolic, and lactonic groups, while $\mathrm{Na}_{2} \mathrm{CO}_{3}$ carboxyl and lactonic, and $\mathrm{NaHCO}_{3}$ only carboxyl groups. The number of surface basic sites was calculated from the amount of hydrochloric acid, which reacts with the biochar ${ }^{17}$.

\section{Adsorption assays: $\mathrm{pH}$ effect and isotherm}

The effect of $\mathrm{pH}$ on CFN sorption by the biochar adsorbents was evaluated. Solutions of CFN at $100 \mathrm{mg} / \mathrm{L}$ were used at five different $\mathrm{pH}: 2.0,4.0$, 6.0, 8.0 and 10.0, $\mathrm{pH}$ was adjusted by addition of $\mathrm{HCl}$ or $\mathrm{NaOH}$. Studies were performed using $5.0 \mathrm{~mL}$ of CFN solution and $50.0 \mathrm{mg}$ of Bchs, which were placed into tubes and shaken in an orbital shaker at $200 \mathrm{rpm}$. The CFN amount were obtained from a calibration curve, using a Thermo Spectronic Genesys 5 spectrophotometer at maximum wavelength of 273 $\mathrm{nm}$. All studies were carried out in triplicate.
The adsorption equilibrium was carried out using CFN solutions at concentrations from 50 to $500 \mathrm{mg} / \mathrm{L}$ at $\mathrm{pH}=2.0$ and 6.0 , and shaking for 72 hours. Studies were performed using $5.0 \mathrm{~mL}$ of CFN solutions and $50.0 \mathrm{mg}$ of Bchs. The CFN amounts adsorbed at equilibrium time, Qe $(\mathrm{mg} / \mathrm{g})$ were determined from the Eq. (1).

$Q_{e}=\frac{V(\mathrm{Co}-\mathrm{Ce})}{W}$

Where $\mathrm{C}_{\mathrm{o}}$ is the initial concentration of CFN $(\mathrm{mg} / \mathrm{L}), \mathrm{C}_{\mathrm{e}}$ is the concentration of CFN at equilibrium, $\mathrm{V}(\mathrm{L})$ is the volume of CFN solution and $\mathrm{W}(\mathrm{g})$ is the dry mass of Bchs ${ }^{18}$.

\section{Adsorption isotherm}

Adsorption isotherm models are a significant approach for the interpretation of how the adsorbent such as biochars will interact and bind with the adsorbate such as CFN. Adsorption models give an idea on the adsorption capacity and play an important role in understanding the possible adsorption mechanisms ${ }^{18}$. Several isotherms are reported in the literature and three models have been tested in this study including Langmuir (Eq. (2)), Freundlich (Eq. (3)), and Redlich-Peterson (Eq. (4)) models were used to fit experimental equilibrium data, determining their parameters and evaluating adjustment quality through determination coefficient $\left(R^{2}\right)^{19,20,21}$.

$$
\begin{aligned}
& Q e=\frac{Q o K_{L} C e}{1+K_{L} C e} \\
& Q e=K_{F} C e^{1 / n} \\
& Q e=\frac{K_{R P} C e}{1+a_{R} C e^{B}}
\end{aligned}
$$

Where $Q_{e}(\mathrm{mg} / \mathrm{g})$ is the equilibrium CFN concentration in the Bchs, $\mathrm{C}_{e}(\mathrm{mg} / \mathrm{L})$ is the equilibrium concentration of CFN in the aqueous phase, Qo $(\mathrm{mg} / \mathrm{g})$ is the maximum adsorption, and $\mathrm{K}_{\mathrm{L}}(\mathrm{L} / \mathrm{g})$ is the Langmuir equilibrium adsorption constant. $\mathrm{K}_{\mathrm{F}}(\mathrm{L} / \mathrm{g})$ is the Freundlich constant or relative sorption capacity, and $n$ is a constant indicating adsorption intensity. $\operatorname{KRP}(\mathrm{L} / \mathrm{g})$ and $\mathrm{aR}(\mathrm{L} / \mathrm{mg})$ are Redlich-Peterson isotherm constants, and $\mathrm{B}$ is the exponent.

\section{Sorption of methylene blue}

Sorption ability of the biochars was performed using methylene blue (MB) solution. $25 \mathrm{mg}$ of each biochar were mixed in $50 \mathrm{~mL}$ tubes with 
$12.5 \mathrm{~mL}$ of $20 \mathrm{mg} / \mathrm{L} \mathrm{MB}$ solution. The slurries, blanks and experimental controls were agitated for $24 \mathrm{~h}$ on an orbital shaker. Measurements of MB concentrations in the filtrates were obtained by a Thermo Spectronic Genesys 5 UV-Vis spectrophotometer at a wavelength of $665 \mathrm{~nm}$. The amount of MB adsorbed, $\left(Q_{\mathrm{e}}\right)$, was determined by Ec.122.

\section{RESULTS AND DISCUSSION}

\section{Surface properties}

\section{Surface morphology (SEM-EDS analysis)}

The SEM micrograph of biochar presented in Fig. 1 [(a)-(f)] shows the heterogeneous surface and an increase in the porosity which is directly related to the increment in the pyrolysis temperature. The observed pores in these carbonaceous materials are usually large macropores, which are used for adsorbates to pass into microporous system ${ }^{3}$. Besides, SEM-EDS is a semiquantitative analytical method and could not provide a full quantitative composition of the organometallic complexes, however, calcium, potassium and magnesium can be detected by SEM-EDS in all biochars. Calcium is the most abundant chemical element found in all materials and their quantity increases when pyrolysis temperature increment. This metallic element were
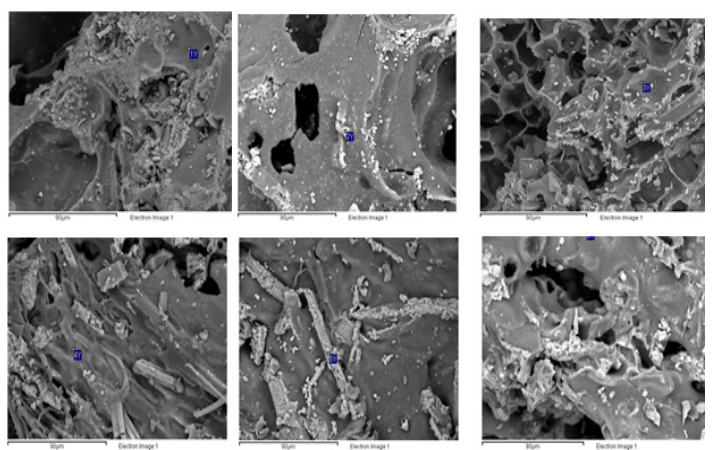

Fig. 1. SEM images of biochar: BchL-650 (a), BchL-750 (b), BchL-850 (c), BchS-650 (d), BchS-750 (e), BchS-850 (f) not uniformly distributed onto the surface of biochars and they are present because most of the minerals in biomass are not lost during the pyrolysis process and remain on biochar structure ${ }^{23}$.

\section{$\mathrm{pH}$, point of zero charge (PZC) and Boehm titration}

Table 1 shows the results of $\mathrm{pH}, \mathrm{PZC}$ and

Boehm titrations. It is observed that all biochars studied in this work have alkaline character, whose value increases when the temperature augment and it can be deduced that the unwashed materials were more basic. These results are in agreement with those obtained by means of the Boehm titrations, where it was evident that there is a greater presence of basic groups in the unwashed materials than in the washed and that the quantity of these groups increased when the temperature rises in the pyrolysis process. This results are also congruent with the results found through the SEMEDX measurements, where the alkaline metals, Calcium, Potassium and Magnesium, were detected, which correlate well with the basic character found in these materials. Regarding the presence of acid groups, it was observed that there was a decrease of them as a function of the pyrolysis temperature, which is closely related to the infrared spectra, in which there was a reduction of the bands at 3600 and 1600 , characteristics of the $\mathrm{O}-\mathrm{H}$ and $\mathrm{C}=\mathrm{O}$ groups. All aforementioned are consistent with that reported by Suliman et al.,(2016), who obtained biochars from three different biomasses at six pyrolysis temperatures and in all cases the concentration of the basic groups increased, while the presence of the acid groups decreased with the increment in the working temperature ${ }^{3}$.

\section{Infrared spectroscopy}

FT-IR spectra of the biochars are shown in Fig. 3. The broad band at $3400 \pm 15 \mathrm{~cm}^{-1}$, which is present in all the worked materials, is a characteristic of the stretch of the hydroxyl groups that are on the

Table 1: pH, PZC and variation in surface acid and total basic functional group of prepared biochars

\begin{tabular}{lcccccc}
\hline Sample & $\mathrm{pH} \pm 0,1$ & $\mathrm{PZC} \pm 0,1$ & $\begin{array}{c}\text { Basic groups } \\
(\mathrm{meq} / \mathrm{g}) \pm \mathrm{SD}\end{array}$ & $\begin{array}{c}\text { Carboxylic groups } \\
(\mathrm{meq} / \mathrm{g}) \pm \mathrm{SD}\end{array}$ & $\begin{array}{c}\text { Lactonic groups } \\
(\mathrm{meq} / \mathrm{g}) \pm \mathrm{SD}\end{array}$ & $\begin{array}{c}\text { Phenolic groups } \pm \text { SD } \\
(\mathrm{meq} / \mathrm{g})\end{array}$ \\
\hline BChL-650 & 8.48 & 9.96 & $3.40 \pm 0.15$ & $1.36 \pm 0.54$ & $0.02 \pm 0.01$ & $0.76 \pm 0.12$ \\
BChL-750 & 9.19 & 10.50 & $3.81 \pm 0.56$ & $1.26 \pm 0.50$ & $0.03 \pm 0.01$ & $0.77 \pm 0.06$ \\
BChL-850 & 10.18 & 10.52 & $4.02 \pm 0.42$ & $1.44 \pm 0.06$ & $0.03 \pm 0.01$ & $0.78 \pm 0.10$ \\
BChS-650 & 11.87 & 12.94 & $4.68 \pm 0.06$ & $0.27 \pm 0.09$ & $0.01 \pm 0.01$ & $0.21 \pm 0.04$ \\
BChS-750 & 12.25 & 13.16 & $4.80 \pm 0.05$ & $0.19 \pm 0.06$ & $0.01 \pm 0.01$ & $0.28 \pm 0.12$ \\
BChS-850 & 13.51 & 13.24 & $5.88 \pm 0.05$ & $0.09 \pm 0.04$ & $0.03 \pm 0.01$ & $0.27 \pm 0.14$ \\
\hline
\end{tabular}


surface of the adsorbents. Small peaks can also be observed at $2930 \pm 10 \mathrm{~cm}^{-1}$, which may be due to the stretch of the aliphatic methylene or methyl groups, the latter confirmed by the signal at $1377 \mathrm{~cm}^{-1}$, which is associated with the stretch of the methyl group. The signal at $1630 \pm 5 \mathrm{~cm}^{-1}$ corresponds to the vibration stretch of the $\mathrm{C}=\mathrm{O}$ bonds. Finally, the presence of the $\mathrm{C}-\mathrm{O}$ bond of the alkoxy, acyl or phenolic groups can be confirmed with the signals at $1103 \pm 4 \mathrm{~cm}^{-1}$ and $1022 \pm 8 \mathrm{~cm}^{-1} 24$. It was also observed in the infrared spectra that the functional groups found on the surface of the Bchs, did not change with the washing that was carried out on the materials, this was also evidenced in other studies ${ }^{25}$.

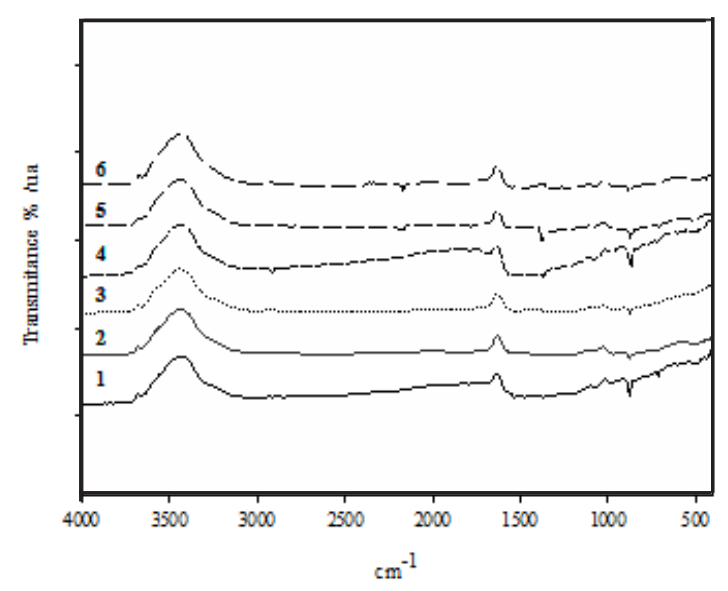

Fig. 2. Infarred spectra of prepared biochars, BchL y BchS (650, 750 y 850$)(1-6)$

Structural characterization: Thermogravimetric analysis

Biochar thermograms can be seen in Fig. 3, which shows that the Bchs have high thermal stability and exhibits the typical degradation of them. The loss of moisture in the range of 50 $100^{\circ} \mathrm{C}$, the degradation of the functional residual groups between $100-350^{\circ} \mathrm{C}$ and finally the graphite formation above $350^{\circ} \mathrm{C}$ were observed. These results are consistent with other investigations on these materials ${ }^{22,26}$.

\section{Caffeine adsorption onto prepared biochars Effect of solution pH on caffeine adsorption}

$\mathrm{pH}$ effect of the solution on the adsorption processes is an important factor because it makes it easy to understand the interaction between adsorbents and adsorbates, since the variation of $\mathrm{pH}$ can promote changes on the surface charges of the former and influence the protonation of functional groups that are on the surface of the latter ${ }^{27}$. In the case of caffeine, at pHs below 5.5 there is a neutral species and above this $\mathrm{pH}$ the negatively charged species begins to appear, being fully present at $\mathrm{pHs}$ above 10.014. On the other hand, the PZC of the worked Bchs was basic (9.96-13.51), which indicates that positive charges over a wide range of $\mathrm{pH}$ values predominate on the surface of these materials. As seen in Fig. 4, the highest values of the adsorption capacity $\left(Q_{e}\right)$ for the L-series biochars were observed at $\mathrm{pH}$ 2.0. These results agree with those reported by Portinho et al., (2017), Couto et al., (2015) and Sotelo et al., (2012), whom using different adsorbent materials, determined that caffeine was removed with greater efficiency, from aqueous acid media ${ }^{11,28}$, which is due to the formation of hydrogen bonds between the adsorbate and the adsorbent, preferably given when the surface of the solid is positively charged ${ }^{29}$.

Meanwhile, for the biochars $\mathrm{S}$ series, the highest $Q_{e}$ values were observed at $\mathrm{pH}=10.0$; however, these values do not show significant differences with the results at $\mathrm{pH}=6.0$, thus indicating that the adsorption of caffeine on these biochars do not have a pronounced dependence at neutral or alkaline $\mathrm{pH}$. These results are consistent with those reported by Portinho et al.,(2017), who found little influence of $\mathrm{pH}$ in the removal of CFN when using activated carbon obtained from grape stem ${ }^{11}$. The above mentioned results lead to infer that the CFN is retained on the Bch thanks to the interactions $\pi-\pi$, which can occur between the heterocyclic rings of the CFN and the aromatic rings of the Bch; likewise, hydrogen bridges can be created between the CFN and the superficial groups of the Bch. The above agrees with the results of Beltrame et al.,(2018) and what has been stated by Tan et al.,(2015), who concluded that in the adsorption of organic pollutants on biochar, hydrogen bonds, Van der Waals forces and $\pi-\pi$ donor-acceptor interactions play a key role in the adsorption process ${ }^{27,30}$. Based on the results previously exposed, it was decided to evaluate the biochar at pHs 2.0 and 6.0, which implies that the work was done on the caffeine in its neutral form. 


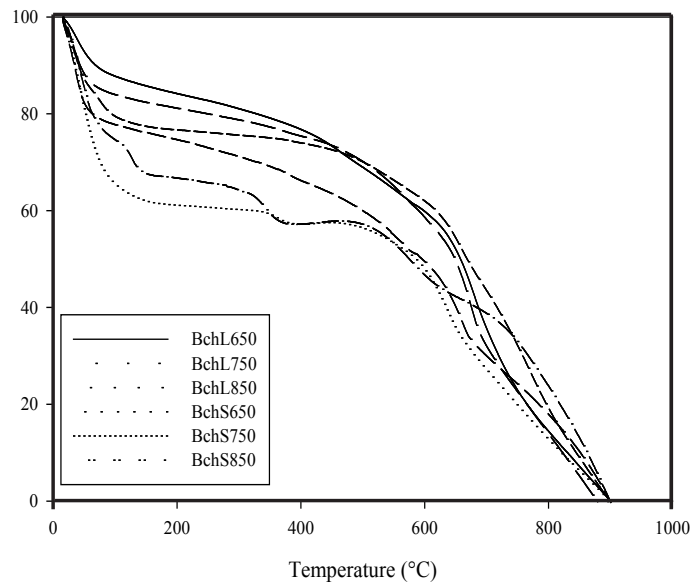

Fig. 3. Thermograms of biochars: BchL y BchS $(650,750$ y 850$)$

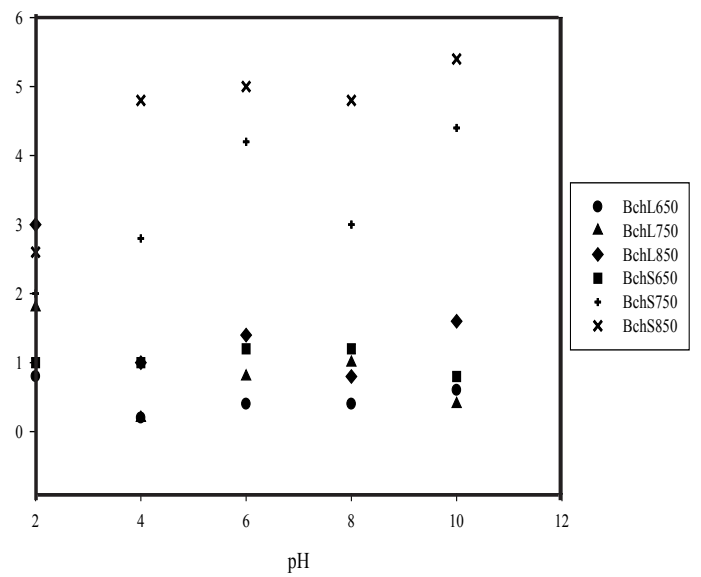

Fig. 4. Effect of solution pH on caffeine adsorption capacity onto BchL y BchS (650, 750 y 850$)$.

\section{Adsorption isotherm}

Results obtained in the investigation show that there is a difference in the amount of CFN adsorbed by the BchL $(\mathrm{Qe}(\mathrm{mg} / \mathrm{g})=1.60-9.00$ and $0.40-3.60$ at $\mathrm{pH}=2.0$ and 6.0 , respectively) and in the $\operatorname{BchS}\left(Q_{e}(\mathrm{mg} / \mathrm{g})=1.40-5.00\right.$ and $0.40-6.40$ at $\mathrm{pH}$ $=2.0$ and 6.0 , respectively). However, in both cases the maximum adsorbed amount increased with the rise in temperature, which makes it possible to infer that this behavior is associated with the porosity of the materials. This correlates with the results obtained with the methylene blue test, in which the Bch850 were the ones with the highest adsorption capacity (Fig. 6), and with the results of Abdul et al., (2017), which obtained the highest adsorption of the esters of phthalic acids with a temperature rise in obtaining the adsorbent materials ${ }^{26}$.

Parameters of the used isotherm models are summarized in Table 2. The comparison of the models based on the correlation coefficient $R^{2}$, made it possible to determine that for the materials worked at $\mathrm{pH}=2.0$, the models that best fit the experimental data were Freundlich and RedlichPeterson, while at $\mathrm{pH}=6.0$ were Redlich-Peterson and Langmuir the better. This also makes it possible to both consider that the adsorption process involved mixed coverage models and infer that the surface of these materials is heterogeneous, with different sites available for adsorption, which have variable adsorption energies ${ }^{31}$.

Table 2: Parameters of Langmuir, Freundlich and Redlich-Peterson isotherms models for caffeine adsorption onto fique bagasse biochar prepared

\begin{tabular}{|c|c|c|c|c|c|c|c|c|c|c|c|}
\hline \multirow[t]{2}{*}{ Sample } & \multirow[t]{2}{*}{$\mathrm{pH}$} & \multicolumn{3}{|l|}{ Freundlich } & \multicolumn{3}{|l|}{ Langmuir } & \multicolumn{4}{|c|}{ Redlich-Peterson } \\
\hline & & $\mathrm{K}_{\mathrm{f}}(\mathrm{L} / \mathrm{g})$ & $\mathrm{n}$ & $\mathrm{R}^{2}$ & $\mathrm{Q}_{\mathrm{o}}(\mathrm{mg} / \mathrm{g})$ & $\mathrm{K}(\mathrm{L} / \mathrm{mg})$ & $\mathrm{R}^{2}$ & KRP (L/g) & $\mathrm{aR}(\mathrm{L} / \mathrm{mg})$ & B & $\mathrm{R}^{2}$ \\
\hline BchL650 & 2.0 & 0.9633 & 3.9119 & 0.9377 & 4.4632 & 0.0318 & 0.8081 & 229358 & 209956 & 0.7676 & 0.9345 \\
\hline BchL750 & & 0.2877 & 2.0657 & 0.9538 & 7.3836 & 0.0056 & 0.9525 & 0.263700 & 0.666279 & 0.5610 & 0.9623 \\
\hline BchL850 & & 0.4520 & 2.1442 & 0.8724 & 8.6483 & 0.0087 & 0.7594 & 1082.77 & 2395.41 & 0.5336 & 0.8725 \\
\hline BchS650 & & 0.3587 & 2.5215 & 0.9466 & 4.7113 & 0.0094 & 0.9084 & 1.11147 & 2.81934 & 0.6182 & 0.9462 \\
\hline BchS750 & & 0.5591 & 3.1078 & 0.9294 & 4.2788 & 0.0152 & 0.8962 & 0.782642 & 1.24046 & 0.6967 & 0.9292 \\
\hline BchS850 & & 0.8190 & 3.3272 & 0.9468 & 5.3480 & 0.0185 & 0.9279 & 0.348880 & 0.281826 & 0.7641 & 0.9489 \\
\hline BchL650 & 6.0 & 0.0350 & 1.5158 & 0.9222 & 3,8096 & 0,0023 & 0,9399 & 0.008554 & 0.001334 & 1.0826 & 0.9415 \\
\hline BchL750 & & 0.0479 & 1.6379 & 0.9103 & 3,5162 & 0.0028 & 0.9342 & 0.008973 & 0.000618 & 1.2219 & 0.9404 \\
\hline BchL850 & & 0.0605 & 1.4770 & 0.9384 & 4.5263 & 0.0068 & 0.9244 & 0.015829 & 0.001180 & 1.0990 & 0.9623 \\
\hline BchS650 & & 0.0254 & 1,3430 & 0.9778 & 5,9300 & 0.0015 & 0.9847 & 0.087340 & 0.001605 & 0.9839 & 0,9846 \\
\hline BchS750 & & 0.3156 & 2.5932 & 0.9264 & 4.0288 & 0.0086 & 0.9327 & 0.0076397 & 0.099996 & 0.7446 & 0.9329 \\
\hline BchS850 & & 0.4518 & 2.2198 & 0.9302 & 9.1296 & 0.0065 & 0.9603 & 0.051611 & 0.002099 & 1.1579 & 0.9657 \\
\hline
\end{tabular}


$\mathrm{BchL} 850 \mathrm{pH} 2.0$

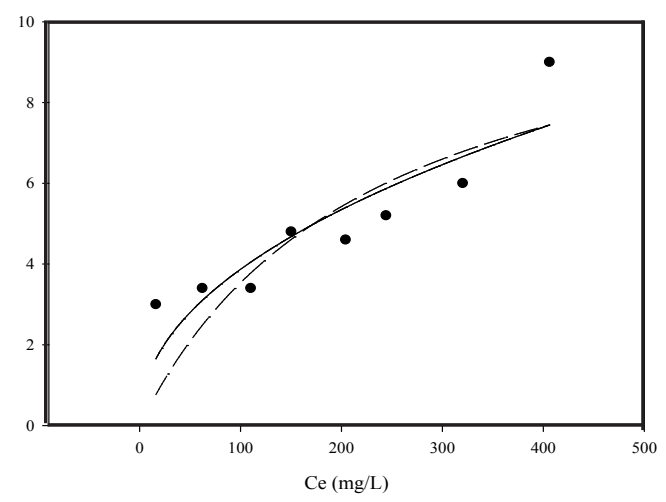

BchS850pH6.0

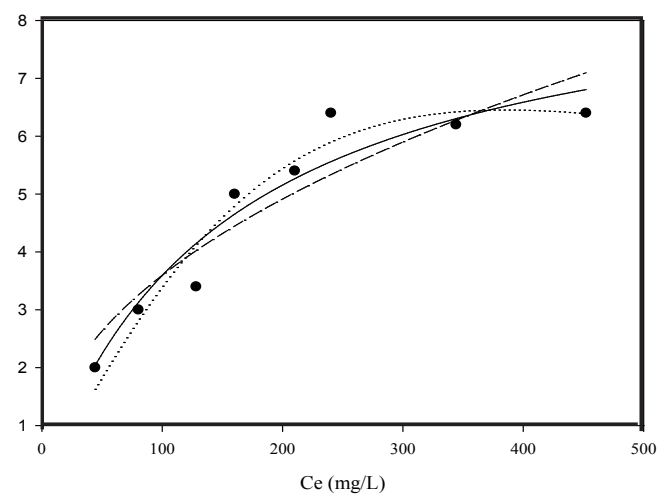

BchS850pH2.0

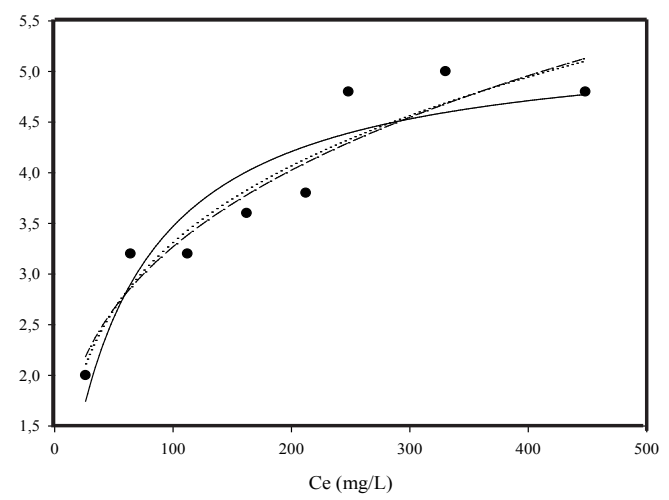

BchL850pH6.0

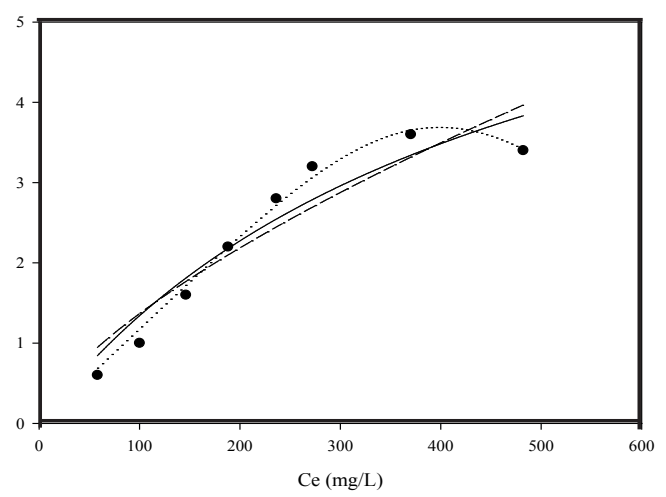

Fig. 5. Adsorption isotherms of caffeine onto biochars 850 at solutions $\mathrm{pH}=\mathbf{2 . 0}$ and 6.0 . Non $\square$ linear fittings of Langmuir, Freundlich and Redlich-Peterson models (- Freundlich, $\square$--Langmuir, ... Redlich-Peterson).

Separation factor or equilibrium parameter $\left(R_{L}\right)$, a characteristic feature of the Langmuir isotherm, is a dimensionless constant, which can be used to determine whether the adsorption is favorable or unfavorable. This parameter was calculated with equation (5):

$R_{L}=\frac{1}{1+K C_{0}}$

In which $\mathrm{C}_{0}(\mathrm{mg} / \mathrm{L})$ was the initial concentration of CFN. In the interpretation of the $R_{L}$ it will be considered that the isotherm will be reversible if $R_{L}=0$, linear if $R_{L}=1$, favorable if $0=R_{L} 1$ or unfavorable if $R_{L} 1$. In calculating this parameter with all the initial concentrations used of CFN, RL values between 0 and 1 were obtained. Therefore, it was concluded that the adsorption process was favorable under the conditions used in this study. Furthermore, given that the value of $n$ obtained in the Freundlich's model was greater than 1, it was deduced that the adsorption of CFN in the worked Bchs was favorable.

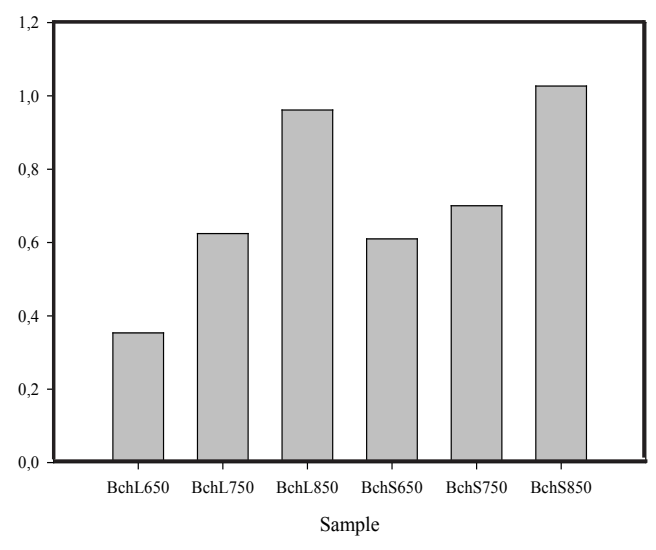

Figure 6. Adsorption capacity of methylene blue on prepared biochars 
Maximum adsorption capacity $\left(Q_{e}\right)$ of CFN determined in this work, $9.12 \mathrm{mg} / \mathrm{g}$, was higher than that found for normal and modified grape stem, which were 0.938 and $2.300 \mathrm{mg} / \mathrm{g}$, respectively, and was close to the one obtained with activated carbon obtained from grape stem $19.575 \mathrm{mg} / \mathrm{g}^{11}$.

However, the $Q_{e}$ of the Bchs were lower than that found with activated carbon fibers obtained from pineapple leaves, which was $152.18 \mathrm{mg} / \mathrm{g}^{27}$ and the values obtained with different activated carbons prepared from Dende coconut and Babassuo coconut, 270.20 and $155.18 \mathrm{mg} / \mathrm{g}$, respectively ${ }^{28}$. Likewise, in the competitive adsorption of caffeine and natural organic matter by an activated carbon synthesized from peach seeds, $Q_{e}$ of 219.20 $\mathrm{mg} / \mathrm{g}$ was obtained ${ }^{14}$, and in another investigation with Calgon Filtrasorb 400 activated carbon, the obtained Qe was of $326.0 \mathrm{mg} / \mathrm{g}^{32}$. It is expected that commercial activated carbons have better adsorption capacities than alternative adsorbents. Likewise, the importance of the chemical or physical treatments carried out on the different evaluated solids was demonstrated and changes in surface chemistry or increase in porosity were obtained, with which the adsorption of CFN was promoted ${ }^{11}$.

\section{CONCLUSION}

Obtained results made it possible to determine that the adsorption of caffeine with the different biochars obtained from the fique bagasse is a complex process, which depends on the adsorbent's characteristics in terms of porosity and chemical composition. Furthermore, it was evidenced that $\mathrm{pH}$ is a determining factor in the elimination of this pollutant from aqueous media and that the predominant forces driving the capture of these contaminants are the formation of hydrogen bonds and the $\pi-\pi$ interactions between the CFN and the surface groups that are present in the Bchs.

For the pHs worked in the adsorption of CFN on the fique bagasse Bchs, the model that best adjusted to the experimental data was that of Redlich-Peterson. Owing to the fact that this model is a combination of the Freundlich and Langmuir models, it can be inferred that the process involved mixed models for the adsorbent coverage.

\section{ACKNOWLEDGEMENT}

Authors thank the Faculty of Ciencias of Universidad de los Andes for the partial funding through the project INV-2018-33-1283 and Universidad de Caldas for studies commission. The authors also appreciate the grant for the funding of research programs for associate professors, Full professors, and Emeritus Professors announced by the Faculty of Sciences of the University of the Andes, 20-12-2019-2020, 2019, according to the project "Enthalpy, free energy and adsorption energy of the activated carbon interaction and solutions of emerging organic compounds".

\section{CONFLICTS OF INTEREST}

by the authors.

No potential conflict of interest was reported

\section{REFERENCES}

1. Kah, M., Sigmund, G., Xiao, F., Hofmann, T. Water Res., 2017, 124, 673-692.

2. IBI. International Biochar Initiative., 2015.

3. Suliman, W., Harsh, J. B., Abu-Lail, N. I., Fortuna, A. M., Dallmeyer, I., García-Pérez, M. Biomass and Bioenergy., 2016, 84, 37-48.

4. Alhashimi, H. A., Aktas, C. B. Resour. Conserv. Recycl., 2017, 118, 13-26.

5. Pal, A., He, Y., Jekel, M., Reinhard, M., Gin, K. Y. H. Environ. Int., 2014, 71, 46-62.

6. Chaukura, N., Gwenzi, W., Tavengwa, N., Manyuchi, M. M. Environ. Dev., 2016, 19, 84-89.
7. Yang, Y., Ok, Y. S., Kim, K-H., Kwon, E. E., Tsang, Y. F. Sci. Total Environ., 2017, 596597, 303-320.

8. Rodriguez-Narvaez, O. M., PeraltaHernandez, J. M., Goonetilleke, A., Bandala, E. R. Chem. Eng. J., 2017, 323, 361-380.

9. Huerta, B., Jakimska, A., Llorca, M., Ruhí, A., Margoutidis, G., Acuña. V., Sabater, S., Rodriguez-Mozaz, S., Barcelò, D. Talanta., 2015, 132, 373-381.

10. Oestreich-Janzen, S. in Encyclopedia of Food and Health., 2016, 556-572.

11. Portinho, R., Zanella, O., Féris, L. A. J. Environ. Manage., 2017, 202, 178-187. 
12. Arrubla, J. P., Cubillos, J. A., Ramírez, C. A., Arredondo, J. A., Arias, C. A., Paredes, D. Ing. e Investig., 2016, 36, 70-78.

13. Escalante, H., Guzmán, C., Castro, L. Dyna., 2014, 81, 74-85.

14. Álvarez-Torrellas, S., Rodríguez, A., Ovejero, G., Gómez, J. M., García, J. Environ. Technol., 2016, 37, 1618-1630.

15. Yakout, S. M. Bioremediat. J., 2015, 19, 171-182.

16. Kodama, S., Sekiguchi, H. Thin Solid Films. 2006, 506-507, 327-330.

17. Boehm, H. P. Univ. Munchen., 2001, 40, 145-149.

18. Awad, Y. M., Lee, S-E., Ahmed, M. B., Vu, N. T., Farooq, M., Kim, I. S., Kim, H. S., Vithanage, M., Usman, A. R., Al-Wabel, M., Meers, M., Kwon, E. E.,Ok, Y. S. J. Clean. Prod., 2017, 156, 581-588.

19. Langmuir, I. J. Am. Chem. Soc., 1916, 22212295.

20. Freundlich, H. Phys. Chem. Soc., 1906, 40, 1361-1368.

21. Redlich, O., Peterson, D. L. J. Am. Chem. Soc., 1958, 63, 1024-1025.

22. Inyang, M., Gao, B., Zimmerman, A., Zhang, M., Chen, H. Chem. Eng. J., 2014, 236, 39-46.
23. Aller, M. F. Crit. Rev. Environ. Sci. Technol., 2016, 46, 1183-1296.

24. Chen, B., Chen, Z., Lv, S. A. Bioresour. Technol., 2011, 102, 716-723.

25. Vardon, D. R., Moser, B. R., Zheng, W. Witkin, K., Evangelista, R. L., Strathmann, T. J., Rajagopalan, K., Sharma, B. K. ACS Sustain. Chem. Eng., 2013, 1, 1286-1294.

26. Abdul, G., Zhu, X., Chen, B. Chem. Eng. J., 2017, 319, 9-20.

27. Beltrame, K. K., Cazetta, A. L., de Souza, P. S.C., Spessato, L., Silva, T. L. Almeida, V. C. Ecotoxicol. Environ. Saf., 2018, 147, 64-71.

28. Couto, O. M., Matos, I., da Fonseca, I. M., Arroyo, P. A., da Silva, E. A., de Barros, M. A. Can. J. Chem. Eng., 2015, 93, 68-77.

29. Sotelo, J. L., Rodríguez, A., Álvarez, S., García, J. Chem. Eng. Res. Des., 2012, 90, 967-974.

30. Tan, X., Liu, Y., Zeng, G., Wang, X., Hu, X., Gu, Y., Yang, Z. Chemosphere., 2015, 125, 70-85.

31. Mahmoud, M. E., Nabil, G. M., El-Mallah, N. M., Bassiouny, H. I., Kumar, S-. Abdel-Fattah, T. M. J. Ind. Eng. Chem., 2016, 37, 156-167.

32. Sotelo, J. L., Ovejero, G., Rodríguez, A., Álvarez, S., Galán, J., García, J. Chem. Eng. J., 2014, 240, 443-453. 